\title{
装配式建筑发展的制约因素及措施研究
}

\author{
孙云祥* \\ 浙江欣捷建设有限公司, 浙江 315000
}

\begin{abstract}
摘 要: 装配式建筑的主要建设形式, 是在施工时将建筑物的构件和材料。通过厂商的预制, 将其运输到施工现 场以后, 进行现场的安装。然后通过浆针或者后浇混凝土的施工形式, 对建筑产品进行有效的连接。与传统的现浇施 工方式相比较, 这种建设方式在应用时, 可以对施工时间进行有效的缩短, 而且可以减少施工人员的劳动量, 提高建 筑物的总体建设质量。但是当前我国建筑行业在发展中, 并没有大力的推广这种装配式建筑, 导致很多施工企业在应 用这种建设形式时，会面临一定的问题。本文就装配式建筑发展的制约因素及措施进行相关的分析和研究。

关键词：装配式建筑；发展的制约因素；措施；分析探讨
\end{abstract}

\section{Research on the Restrictive Factors and Measures of the Development of Prefabricated Buildings}

\author{
Yun-Xiang Sun* \\ Zhejiang Xinjie Construction Co., Ltd., Ningbo 315000, Zhejiang, China
}

\begin{abstract}
The main construction form of prefabricated building is to install the components and materials of the building on site after they are prefabricated by the manufacturer and transported to the construction site. Then through the construction form of slurry anchor or post cast concrete, the construction products are effectively connected. Compared with the traditional cast-in-place construction method, this construction method can effectively shorten the construction time, reduce the labor of construction personnel, and improve the overall construction quality of the building. However, in the current development of China's construction industry, there is no strong promotion of this kind of prefabricated building, resulting in many construction enterprises in the application of this form of construction, will face certain problems. In this paper, the constraints and measures of the development of prefabricated buildings are analyzed and studied.
\end{abstract}

Keywords: Prefabricated building; development constraints; measures; analysis and discussion

\section{一、前言}

虽然我国的施工企业在进行装配式建筑建设时，还存在较多的问题，但是这种建筑形式，已经成为整个行业的发 展趋势。因此施工企业必须根据工程建设时, 存在的一些制约因素, 结合国内外先进的建设经验, 制定科学有效的解 决措施, 使得装配式建筑能够获得更好的发展。政府也要支持这项工程的建设, 通过制定相关的优惠政策, 促进企业 的发展。企业也要从内部制定完善的技术体系, 引进更加先进的施工技术和设备, 在进行这项工程建设时, 才能保证 各个施工环节能够顺利的进行, 为施工企业带来更多的综合效益 ${ }^{[1]}$ 。

\section{二、装配式建筑发展的制约因素}

(一) 现有的产业链内容不够完善

当前在进行装配式建筑建设形式应用时, 相关的建设模式并不成熟, 施工企业只能应用软件对工程进行设计。在 进行生产加工和构件安装时, 施工企业并没有对相关的环节进行重点管理。后期在开展构件的组装和维护等工作时。 也存在较多的问题。施工企业也没有建立完整的产业链, 在进行工程建设时, 依然采用了传统的管理模式。很多设计

*通讯作者: 孙云祥, 1986年1月, 男, 汉族, 浙江临海人, 现任职于浙江欣捷建设有限公司, 中级工程师, 二级 建造师, 本科。研究方向：建筑施工。 
单位和构件的生产企业, 并没有与施工企业进行协调作业。在进行工程建设时, 无法通过各部门之间的团结合作, 促 进工程的顺利建设, 导致工程的总体建设效率比较低。在对工程进行管理时, 存在更多的困难, 甚至会增加工程的施 工费用。而且很多中小型的施工企业没有能力进行产业链的建设，制约了工程项目的发展 ${ }^{[2]}$ 。

(二) 建设完成的工程存在一定的质量问题

现阶段施工企业在进行装配式建筑建设时，主要采用了混凝土预制的施工措施。但是在实际建设时，施工企业没 有建立完善的质量管理体系, 甚至很多时候企业在应用施工技术的时候, 并没有根据工程的建设要求, 选用正确的施 工技术，导致施工技术的应用存在较多的问题。在工程建设的各个环节，施工企业并没有建立完善的技术标准，这就 导致工程的建设质量, 得不到有效的提高。一般来说在进行这种工程建设中, 存在的质量问题, 主要是因为构件的安 装和制作出现问题。或者在进行灌浆作业时, 施工人员没有严格按照工程的建设要求, 开展各项操作, 导致作业质量 得不到提高。在进行构件组合安装时, 没有对安装的位置进行明确, 安装之后的空间尺寸, 不符合应用的要求, 也会 导致质量问题的出现，在后期对成品进行维护时，如果维护工作的开展，无法发挥应有的效果，也会增加质量问题的 发生概率 ${ }^{[3]}$

（三）BIM技术的应用水平比较低

施工企业在进行装配式建筑工程建设时，应用BIM技术，可以通过三维模型的建立，对工程的设计和维护整个过 程的信息数据进行及时的提取, 还可以对数据信息进行处理后, 实现资源的共享。参与工程施工的各单位, 也可以通 过模型的应用，对工程的建设效果进行模拟，对施工时可能出现的各项问题进行预测和解决。实际上这项技术在应用 时, 可以提高工程建设的协调性。但是当前很多的施工企业在进行工程建设时, 并没有认识到这项技术应用的重要 性。虽然这项技术在我国建筑行业中，已经进行了大力的推广，但是真正应用这项技术进行工程建设的项目比较少。 很多施工企业自身的信息技术水平比较低，在进行工程建设时，无法对先进的技术进行有效的应用。这种情况的出 现，也会制约装配式建筑的发展 ${ }^{[4]}$ 。

而且施工企业在进行工程建设时, 并没有根据构件的成分, 建立相应的设计规范和标准。在进行工程建设时, 没 有建立统一的设计标准, 导致工程建设的中心并不明确, 降低了构件成分的合理性。甚至在进行工程建设时, 现有的 监测手段比较低下，无法对构件进行优化。在进行工程施工时，经常会出现构件的质量问题，这些问题都会制约工程 的发展。在进行吊装和运输作业时, 如果存在问题, 就会导致构件在后期应用时, 出现裂缝等问题, 会降低结构应用 的安全性。而且施工企业也没有对各个环节的施工重点和难点进行明确, 应用的施工技术不符合工序的操作要求。施 工企业也没有加强技术的研发，导致企业的施工水平得不到提高 ${ }^{[5]}$ 。

（四）缺乏相应的政策法规

当前我国在进行装配式建筑工程应用时，虽然对这项建筑形式进行了推广。政府也出台了相应的法规条例，推动 这项工程进行了更好的发展。但是我国并没有对这项工程的建设, 进行具体的要求。政府也没有制定相应的法律法 规, 对工程建设质量的各项问题进行约束。导致施工企业在进行工程建设时, 出现了更多的问题, 不仅降低了施工质 量和使用功能，而且会阻碍这项工程的发展 ${ }^{[6]}$ 。

（五）整个行业对其缺乏正确的认知

在进行装配式建筑工程施工时，从工程的开发商和设计人员到居住人员，都对装配式建筑结构的稳定性和抗震 性, 提出了更高的要求, 特别是在我国地震灾害频发阶段, 这种装配式建筑的结构, 会造成严重的破坏。在遭受外力 破坏时, 一些预制的构件, 会出现裂缝和渗漏的情况, 而且会降低结构的保温和隔热性能。所以这种结构与原有的结 构, 还存在较大的差异, 导致很多居住人员对这种结构的应用缺乏信心。因为缺乏强有力的市场, 所以, 开发商在进 行这种建筑开发时, 甚至放弃进人市场。在进行工程建设时, 如果设计人员没有对这种建筑存在正确的认知, 在进行 设计方案制作时, 各项内容缺乏合理性, 就会导致建设完成的工程难以满足应用的需求。而且在进行工程建设中, 设 计方案必须遵循个性化和艺术化的设计标准。如果设计人员在开展工作时, 没有对结构的平面规则进行合理的布置, 就会导致后期建筑物建设完成之后，缺乏造型的艺术感。同时建筑物的功能也不够完善，在应用时不仅无法满足居民 的居住需求，而且功能的使用，会出现更多的问题，加大了工程的维护工作量 ${ }^{[7]}$ 。

( 六 ) 受到了传统施工模式的制约

在进行建筑工程建设时，传统的施工模式，从施工技术到工程管理，各个方面都已经发展成熟。相关部门的人员 
在进行工程建设时, 具备更加丰富的经验。设计单位和施工企业以及监理单位，也可以按照预期的模式来运行。在应 用装配式施工模式时, 要改变原有的建设理念和管理方式, 还需要吸引更多的优秀人才。在施工时还要应用一些新型 的技术和设备, 才能保证装配式工程的建设规范和标准。因为在进行这种工程建设时, 属于新型的建设方式, 所以, 相关的人员要对技术和理念进行学习, 才能保证工程的建设顺利完成。因此施工企业在进行工程建设时, 前期要投人 大量的资金，也无法在短时间内获取相应的收益。所以，很多施工企业不愿意放弃原有的建设模式，学习这种新型的 施工模式, 这种情况的出现, 也制约了装配式建筑工程的发展 ${ }^{[8]}$ 。

（七）工程的建设成本比较高

在进行建筑工程建设时, 施工成本比较高, 严重阻碍了这项工程的发展。导致工程建设成本不断增加的原因, 是 在进行构件生产时, 生产基地的建设, 需要投人大量的人力和物力资源。而且前期的生产线建设, 需要投人较多的资 金。只有一些大型的施工企业有能力投资建设, 一些中小型企业没有能力进行生产线的建设, 所以构件的生产数量比 较小, 容易形成垄断的现象。在进行构件生产时, 出厂的构件属于商品, 所以要缴纳一定的增值税。而其他的建筑材 料, 也要缴纳相应的税费。这些高额的税费要由消费者承担, 这也在无形中增加了工程的建设成本。因为当前在进行 这种工程建设时, 没有对构件的生产进行统一的规范, 在进行构件设计和生产以及运输时, 缺乏统一的标准。在开展 工程管理工作时，也存在一定的困难。在这个过程中，施工成本会不断地增加 ${ }^{[9]}$ 。

\section{三、装配式建筑发展的推广措施}

（一）建立相应的行业协会

要想促进装配式建筑工程进行更好的发展, 施工企业可以形成产业联盟, 组建更加完善的产业链。建筑行业协会 应该对这项工程的建设进行大力的推广, 并且促进企业联盟的建设和发展, 可以培育一定规模的企业联盟, 使其建立 更加完整的产业链。在进行建设时, 还可以通过政府的功能发挥, 鼓励大型的施工企业, 建立符合自身发展需求的产 业链，通过优势的互补，促进企业之间的合作和交流，使得企业能够联合起来，共同地进行工程的建设 ${ }^{[10]}$ 。

\section{(二) 加强质量管理}

在进行装配式建筑工程建设中, 要想提高工程的整体施工质量。施工企业应该在工程建设之前, 就对可能出现的 质量问题进行预防, 在施工阶段应该做好现场的管理, 对各个工序的施工行为, 进行有效的控制。在工程建设完成之 后, 还要对工程的施工经验进行总结和归纳, 从而保证工程的建设质量能够得到提高。要对工程的建设全过程进行动 态的控制，才能充分发挥质量管理工作的效用，确保工程的各个施工环节的建设质量，能够符合相应的标准。

如图1图2所示, 在开展前期准备工作时, 要对构件的信息进行准确的核对, 还要对预埋件和钢筋材料的建设位置 进行检查。要对施工情况进行规范, 还要对构件的外部缺陷问题进行检查, 确保构件合格之后才能应用。要对构件的 尺寸进行测量, 在对构件进行抽查和检验时, 要对检验的标准进行提高, 确保工程的施工方案符合相应的建设要求。 在进行工程竣工验收时, 要对构件的安装质量和建设位置, 进行认真的检查, 确保施工作业符合建设的要求。还要保 证针固钢筋等材料的应用, 符合相应的规定。对工程进行验收时, 要对施工材料的完整性进行检查, 确保隐蔽工程的 建设，符合相应的质量标准。相关人员还要对部分工程的验收情况进行核查，提高成品的保护质量。

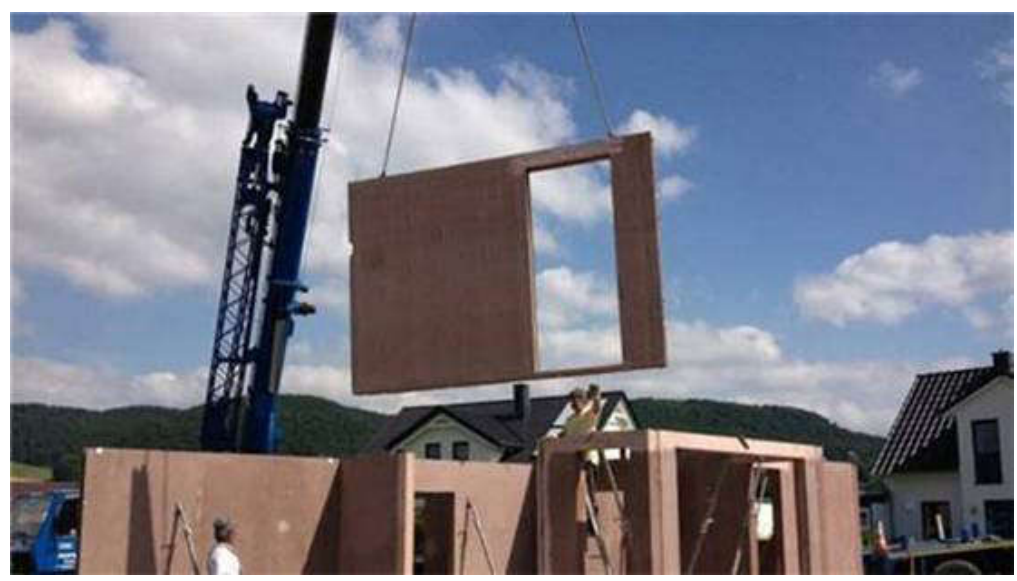

图1 构件安装 


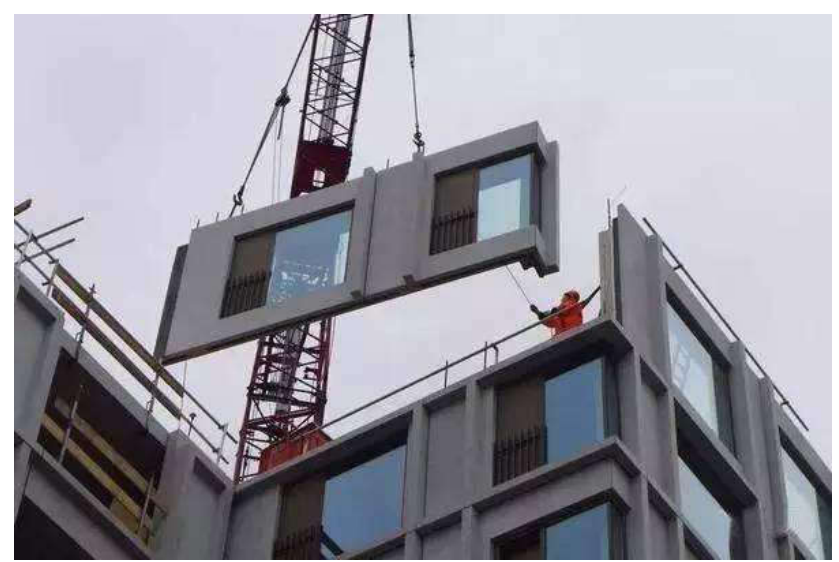

图2 应用构件进行工程建设

(三) 加强技术的研发

如图3所示, 在进行装配式工程建设时, 施工企业必须认识到信息技术应用的重要性, 通过应用BIM技术进行工 程的设计。在设计时可以建立三维模型, 提供多个数据端口, 让不同的建设单位参与到工程的设计中。在设计方案完 成之后, 可以提供相应的图纸, 对各个构件的建设信息, 进行准确的描述。如果在开展碰撞检查实验时, 发现存在冲 突的问题, 要对这些问题进行及时的调整, 并且制定完善的预防措施。在进行工程造价管理时, 可以用这项技术提供 造价管理工作的精度, 将其控制在可控的范围内, 还可以对估价的时间进行缩短。在进行构件生产时, 可以对生产信 息进行全面的管理。构件的生产企业也可以通过端口, 获取相应的信息, 企业可以在构件中放人芯片, 通过引进相关 的技术, 对构件的应用数量和建设位置进行实时的了解。还可以对构的运输信息和组装信息, 进行全面的了解。在进 行构件组装时，可以将BIM技术与其他技术进行有机结合，避免在应用构件时，用量发生错误或者出现丢失的问题。

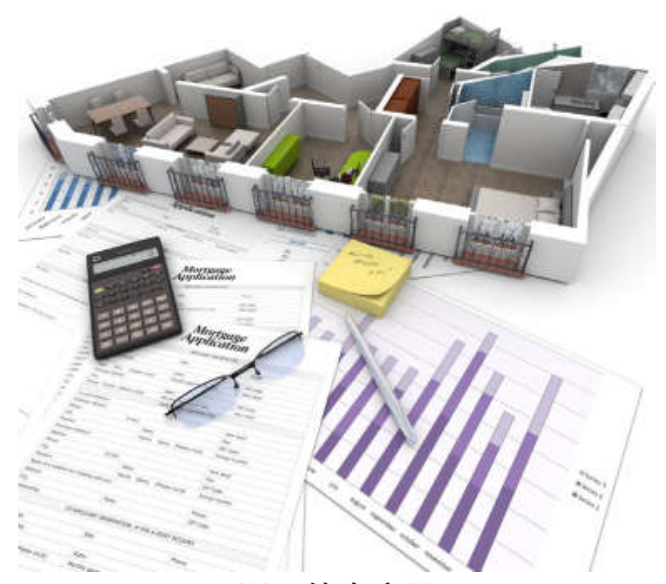

图3 技术应用

（四）制定完善的法律法规

当前在进行装配式建筑工程建设时, 要求对顶层设计工作进行完善。政府要建立更加完善的法律法规体系, 为施 工企业提供法律保障。政府应该充分发挥自身的职能, 将各个企业联合起来, 建立统一的机构, 对工程的施工单位进 行协调管理，确保工程建设更加的顺利，政府还可以制定更加完善的法律法规，成立专项基金对工程建设进行扶持。 还可以鼓励相关的人员，学习新型的技术，为这项工程的发展，奠定良好的基础。

(五) 引进优秀人才

在进行装配式建筑工程建设时, 人才的应用对工程的建设质量, 具有重要的影响。因此施工企业必须吸引优秀的 人员, 并且做好人员的培训和教育工作, 组织施工人员学习新型的技术。如果一些建设程序对于技术的要求比较高, 企业可以在能力范围内, 引进一些优秀的人才, 提高企业的整体技术水平。施工人员也应该加强技术的学习, 根据市 
场的导向学习新型的技术。在装配式建筑工程不断推广的过程中, 很多企业缺乏相应的技术人才, 特别是能够应用 BIM技术的人员。因此，社会各界要根据人才的需求，为相关企业培养更多的人才，避免劳动市场的供需失衡。

(六) 创新建设形式

当前在进行装配式建筑工程建设时, 应该对工程的建设形式进行创新, 相关人员既要在施工技术方面进行创新, 还要创新现有的管理工作。在进行工程建设时, 投资的企业要对建设的模式, 进行创新和优化, 例如应用PPP模式进 行工程的建设。在进行构件生产时, 要对技术进行全面的管理, 并且对现有的管理内容进行创新。还要创新运输方式 和组装技术，确保工程的建设更加的协调。施工企业也可以对技术的应用和验收标准进行创新。

（七）加强施工成本管理

在进行工程建设时, 施工成本管理工作的开展是非常重要的。不仅可以提高工程的建设效率和质量, 还可以降低 工程的施工成本，缩短工程的建设时间。因此施工企业在进行工程建设时，一定要对各个施工程序进行全面的管理， 才能保证工程的建设成本, 能够得到有效的降低。施工企业还可以应用一些新型的材料和设备, 加强材料和设备的管 理，从而提高工程的建设效益。

\section{四、结语}

综上所述, 施工企业在进行建筑工程建设时, 传统的施工模式存在较多的问题, 不仅无法提高工程的总体建设质 量, 而且会增加工程的施工成本。随着装配式建筑工程的推广使用, 这种建设方式, 不仅能够满足工业化的建设需 求。而且能够提高建筑物的施工质量, 使得建筑物在应用时, 更加的安全稳定。在施工时可以节约工程的建设成本, 提高工程的生产效率, 使得建设完成的建筑物, 能够满足节能环保的应用需求。因此, 施工企业在进行工程建设时, 一定要认识到这项工程建设的重要性, 并且通过相关技术的实践, 促进技术的发展成熟。为我国装配式建筑的发展, 提供有效的支持。

\section{参考文献:}

[1]董国庆,杨会东.装配式建筑工程项目管理中存在的问题及对策分析[J].居舍, 2019(30):142.

[2]培育与装配式建筑发展相适应的人才队伍推动建筑业提质增效和装配式建筑健康发展 [J]. 住宅产业, 2019(09):18-26.

[3]江珊.我国装配式建筑推广实施的制约因素及对策研究[J].北京建筑大学, 2019 .

[4]幸蜀嘉.装配式建筑发展的制约因素及其推广措施浅谈[J].建材与装饰, 2018(44):156-157.

[5]梅樹,张哨军,夏萌.装配式建筑发展的制约因素及其推广措施[J].工程经济, 2018,28(07):47-50.

[6]黄诚,彭依依,周海峰,周敏.装配式混凝土建筑发展制约因素及其对策研究 [J].现代物业(中旬刊), 2018(05):78.

[7]张龙雨.基于系统动力学的安徽省装配式建筑发展影响因素及推进策略研究[J].合肥工业大学, 2018.

[8]高路.BIM技术在预制装配式建筑设计及其绿色施工中的应用研究[J].安徽建筑大学, 2018.

[9]田东方.BIM技术在预制装配式住宅施工管理中的应用研究[J].湖北工业大学, 2017.

[10]朱百峰.装配整体式建筑绿色度评价体系研究[J].沈阳建筑大学, 2016. 